\title{
Training for visiting registrars: experience in East Anglia, UK
}

\author{
PF Jenkins, JSG Biggs
}

\begin{abstract}
Summary
A questionnaire was sent to 24 visiting registrars in East Anglia to obtain information on their perceptions of their training experiences. The results suggest that the needs of overseas doctors and the requirements of training authorities would benefit from organisational changes aimed at improving selection and training programmes. Formal training programmes are needed, tailored to an individual's requirement, with identification of educational supervisors for each trainee. An improved system of introduction to the National Health Service is also required.
\end{abstract}

Keywords: training

The revision of specialist medical training in the UK is an area of much active discussion. The next decade will see the introduction of radical changes in the way medical graduates are trained for careers in the hospital service, and many of these changes are embodied in the proposals of the Calman report. ${ }^{1}$

The advent of career packages with a continuum of medical training, and the formal structuring of training programmes for hospital doctors is welcome, but major problems will need to be addressed as these changes are introduced. One of these problems is the need to support busy clinical service commitments in the hospitals while meeting the exigencies of training junior hospital doctors in the National Health Service (NHS). ${ }^{2}$ A connected problem is that of the discrepancy between the numbers of individuals who can be trained for career posts in the hospital service and the greater number of pairs of medical hands who are required to look after patients on a day-to-day basis. It seems likely that there will continue to be heavy reliance upon qualified doctors from other countries, individuals who will occupy so-called visiting posts in the hospital training grades. These doctors will continue to work in parallel with UK and other European Union (EU) graduates in the training grades and, in return for their service work, they should receive postgraduate training of an equal standard.

There are increasing reports of problems encountered by overseas qualified doctors, ${ }^{3-5}$ some of which relate to problems in obtaining training posts and some to the difficulty which they experience of adjusting quickly to a different health service and different approaches to delivery of health care ${ }^{6-8}$ There are also problems with the quality of training received and with terms and conditions of service offered by health authorities..$^{9-16}$

The ideal training programme for non-EU, overseas doctors will vary, depending on specialty, but areas often seen as needing improvement include the selection of individual overseas doctors for specific training programmes and acclimatisation support for doctors when they first arrive in the UK. Also vital is the provision of systematic training with attention given to the length of the programme and the balance between preparing for higher examinations and the acquisition of specific skills. To investigate these and other issues, we undertook a survey in 1993 of the attitudes of visiting registrars towards their training arrangements and their satisfaction with the teaching they had experienced in the East Anglian region.

\section{Methods}

One of us (PJ) contacted consultant staff committees and clinical tutors in the district general hospitals and the teaching hospital in East Anglia and, after agreement was obtained for the project to proceed, individual visiting registrars were contacted and interviewed at their place of employment using a structured format, a copy of which is available from the authors.

Both open and closed questions were designed to investigate individuals' perceptions of their training experiences and the priorities they attached to various aspects of an ideal training programme. Training was considered under three headings: formal preparation for examinations, experiential training (ie, supervised 'training on the job'), and the acquisition of special skills.

\section{Results}

Twenty-four of the 30 visiting registrars in this region were interviewed of whom 19 were male and five female. Their mean age was 33.5 years (range 28 to 41 years). Six individuals were married and had families with them. The doctors interviewed were from Pakistan (3), India (3), Ghana (2), Hungary (2), Malaysia (2), Nigeria (2), and one each from Australia, Burma, Egypt, Iraq, Jordan, Libya, Malta, Sudan, Syria and USA. Twenty-two of the 24 interviewed planned to return to their home 
country after completing a period of postgraduate training in the UK. Specialties represented in the study were obstetrics and gynaecology (8), general medicine (5), surgical specialties (5), psychiatry (2), anaesthetics (2), orthopaedic surgery (1), and paediatrics (1).

\section{FORMAL TEACHING}

There was a wide range of opinion but only nine of the 24 registrars felt that they had received good or excellent training in preparation for examinations. Several commented that formal teaching was insufficient to allow them to meet the requirements for UK examinations. A common problem was fulfilling a heavy clinical workload while retaining sufficient time for formal study. In the majority of cases (17 out of 24), study leave was available but in some specialties (particularly in obstetrics and gynaecology and the surgical specialties), insufficient time was available for attendance at pre-examination and postgraduate courses, largely due to heavy service commitments.

\section{EXPERIENTIAL TRAINING}

Sixteen of the 24 registrars considered that experiential training had been good or excellent. Four considered that 'training on the job' had been fair while four commented that their supervision and general experiential training had been poor and that the clinical demand was such that adequate supervision had been very difficult to achieve.

\section{SPECIAL SKILLS ACQUISITION}

This appeared to be the least successful aspect of postgraduate training, only eight of those interviewed considering they had received good or excellent training in special skills which they had been seeking in the UK. In the majority of cases, support from consultant staff and colleagues was available, but organisation and funding difficulties did not allow the acquisition of special skills (eg, in minimally invasive surgery). The response to the question whether this aspect of training would have been improved by rotation to a teaching centre was invariably 'yes'.

\section{GENERAL COMMENTS}

Each interviewee was asked about further specific aspects of their training. All were in favour of the concept of educational supervision, defined as formal and regular supervision by a senior doctor who would set achievement standards and assess progress.

The majority (18 out of 24) were in favour of a preparatory period to acclimatise to UK medicine. Opinions varied as to the optimum length of time for such a period, but the average suggested time was eight weeks.

Twenty-three of the 24 registrars were in favour of rotation schemes within a region; a rotation into the teaching centre would be of great advantage. The exception amongst those interviewed had come to the UK specifically to gain 'hands on' clinical experience as found in a District General Hospital.

Opinion varied as to the optimum amount of time to be spent in the UK. A significant proportion of those interviewed felt that four years was sufficient, exceptions being those in the surgical specialties who had come to the 0 UK to obtain a Fellowship and to acquireon special skills. Passing Fellowship was difficult and often required half of their allowed time in气 the UK. Difficulty was then experienced in obtaining registrar posts, the only grade at $\cong$ which special skills were likely to be obtained. Understandably, these individuals felt that as longer period of attachment in this countryo would be beneficial.

The majority considered that the system for ${ }^{\frac{\bar{T}}{5}}$ employment after arrival in the UK was too haphazard and that there would be great advantage in acceptance from their country of $\overrightarrow{ }$ origin into a specific formal training programme.

Sixteen of the 24 registrars considered that the relationship between consultant and regis $\frac{0}{7}$ trar grade had been very good. One reported $a$. bad relationship and seven considered that $N$ their relations with senior colleagues had beenơ indifferent at best.

The overall impression of the interviewed visiting registrars was that of a highly motivatedo and capable group of people who had chosen aperiod of postgraduate training in the UK. Thes way in which healthcare was delivered in the $\mathbb{D}_{\mathbb{P}}$ UK was admired by all of the doctors inter- $-\frac{\mathbb{D}}{3}$ viewed; they considered the ethos of medicalo care was something with which they could identify and which would benefit their profes- 8 sional careers in their own countries. $A$ ? number, however, had been disappointed with the training received, a disappointment which stemmed from lack of organisation rather than lack of commitment from their trainers. In $a \%$ minority of cases supervision during training $\cong$ had been seriously deficient.

\section{Discussion: suggestions for improvement}

The needs of visiting registrars will vary흘 according to their chosen discipline. Passing. the Fellowship examination is given a high 3 priority in the surgical specialties but acquisition of specific skills is also vital and a four-year training period may be too short. An alter-o native approach to selection of trainees is that they be taken into UK training programmes at: a stage when they have a qualification equivalent to a Fellowship and are accepted as being. trainable for special skills at registrar, or in the $\tilde{O}$ future at specialist registrar, ${ }^{1,17}$ level. In other $\omega^{\prime}$ specialties, four years training was perceived to be adequate by the trainees.

Doctors arriving in the UK are often $\frac{\text { D }}{\Phi}$ inadequately supported during acclimatisation ${ }^{\text {? }}$ and introduction to training. It is very difficult ${ }^{-}$ for overseas doctors to organise a training $\underset{\mathbb{\Phi}}{\stackrel{D}{*}}$ programme on their own when they are thrown $\frac{}{1}$ into the melee of recruitment in competition $\cong$ with others from abroad and often with career registrars. Progress during four years of train- 0 ing relies more often than not on chance rather than ability. Some doctors find themselves in unsuitable posts, where they are used to fulfil ${ }^{\risingdotseq}$ service load but receive very little training. 
This survey shows commitment by many consultants to supervision and training of individual visiting registrars, but it seems clear that the organisation and structuring of training programmes can be much improved.

The following recommendations are supported by the results from this survey:

- A new scheme of registrar training programmes for overseas doctors should be developed in the UK through relationships forged with particular teaching hospitals in other countries. Prospective trainees of high calibre could then be interviewed for entry into these programmes, ensuring that graduates likely to succeed are chosen and thus avoiding the burdens upon overseas doctors of finding suitable posts when they arrive in a new country.

- Formal training programmes for overseas graduates are essential and the development of career packages for higher trainees in the Calman ${ }^{17}$ system offers the opportunity to plan similar training programmes for visiting graduates, giving due attention to the needs

1 Department of Health. Hospital doctors: training for the future. The report of the working group on specialist medical training. (The Calman Report). London: HMSO, 1993.

2 Hale R, Hudson $L$. The Tavistock study of young doctors: report of the pilot phase. Br $\mathcal{F}$ Hosp Med 1992; 47: 452-64.

3 Anon. Overseas doctors' training scheme: an unforgettable Anon. Overseas doctors' training scheme: an unfo

4 Paton A. A better deal for overseas doctors? Postgrad Med $\mathcal{F}$ 1988; 64: 87-8.

5 Wakeford R, Faroogi A, Rashid A, Southgate L. Does the WRCGP examination discriminate against Asian doctors? $B M \mathcal{F}$ 1992; 305: 92-4

6 Arunabh. Foreign medical graduates. Acad Med 1989; 64: 668.

7 Khan IH. Language tests for EC doctors. Lancet 1992; 339: 935-6.

8 Anon. Surgical training in the UK for doctors from overseas. Lancet 1987; 1: 1071-2.

9 Bevan PG. The overseas doctors training scheme in surgery. Br f Hosp Med 1990; 43: 11. for formal training, experiential training and the acquisition of special skills. There should be flexibility in apportioning each of these requirements for particular individuals and this will be helped by a selection of candidates at source, as mentioned above.

- A period of acclimatisation to UK medicine should be mandatory and part of any regional programme.

- Since a number of doctors experience financial problems when they move to the UK it should be a Trust responsibility to ensure that adequate housing, etc, is available for the doctor and his family.

Overseas doctors will be needed by the NHS for the foreseeable future; exploitation is in noone's interest, but the development of career programmes should benefit all, and parallel training for overseas doctors and our own graduates should provide valuable experience for all medical staff in the hospital service.

Our grateful thanks to Mrs C Marples for help in producing this manuscript.

10 Chisholm GD, Todd I, MacArthur J, Kneafsey D. Surgical examinations. Lancet 1989; 1: 1454.

11 Gibberd FB. Testing overseas doctors. BMF 1988; 297: $155-6$.

12 Lister J. The impact of overseas medical graduates on service and training in the United Kingdom. $N$ Engl $f$ Med 1986; 315: $1038-40$

13 Anon. Overseas medical graduates in the United Kingdom. N Engl ₹ Med 1987; 316: $1094-5$.

14 Rowley DI. Do overseas doctors receive appropriate training? Br f Hosp Med 1990; 43.

15 Towers PL. British diplomas and limited registration. Lancet 1989; 1: 1204.

16 Williams DI. Overseas doctors and the staffing structure of hospitals. BMF 1989; 291: 873-6.

17 Department of Health. A guide to specialist registrar training. London: HMSO, 1995. 